\title{
REMEEDIOS PROCESSUAIS DA ADMINISTRAÇÃO E CONTRA A ADMINISTRAÇÃO
}

\author{
Galeno Lacerda \\ Professor Catedrático da Faculdade de \\ Direito de Pôrto Alegre da Universidade \\ do Rio Grande do Sul
}

Há muito de verdade na errônea afirmação de BINDER (1) de que a actio é um prius em relação ao direito subjetivo. Para êle, tôda sentença, mesmo meramente declaratória, tem função constitutiva, visto ser sempre hipotético o direito alegado pelas partes. O objeto do processo não se constituiria, assim, de uma relação material pré-existente, senão que, tão só, de uma simples afirmação jurídica. Por isto, o direito subjetivo seria um posterius.

Esta teoria da prioridade lógica da actio, com tanta razão criticada por PUGLIESE (2), não é, contudo, de todo desprezível.

O processo é, sem dúvida, um meio de aferição de juízos de valor. Podemos afirmar que através dêle se cria também o direito, no sentido, próprio de nossa contingência, de descoberta da norma adequada aos fatos controvertidos. Da análise valorativa da prova, a inteligência induz, pọr abstração, a norma jurídica, descobre o dever - ser imposto pelos valores em conflito.

Isto explica a razão pela qual a actio romana, como o commonlaw anglo-americano, constituem fontes inesgotáveis

\footnotetext{
(1) - "Prozess und Recht", 1927, pág. 49, e "System der Rechtsphilosophie", 1937, pág. 355.

(2) - "Actio e diritto subiettivo", 1939, págs. 42 e segs.
} 
de elaboração do direito. É que a variedade infinita dos litígios e a complexidade cada vez maior dos interêsses obrigam o juiz, como o cientista que pesquisa o real, a conhecer e descobrir o direito.

A monumental construção do direito romano resulta, sem dúvida, do repositório de fórmulas coligidas durante séculos. E que era a fórmula senão a norma jurídica abstrata implìcitamente anunciada e descoberta pelo pretor, em face da valorização por êle elaborada dos fatos trazidos a seu conhecimento pela litiscontestatio?

A actio não é um prius do direito subjetivo, como pensa BINDER. Mas foi, sem dúvida, e continua a ser, um dos meios mais eficazes de a razão humana encontrar-se com o direito objetivo. Êste pré-existe ao processo, está ínsito nos valores em litígio, como causa do direito subjetivo de qualquer das partes, que, afinal, venha a ser declarado pelo juiz.

A actio não é, na verdade, prius, nem lógico, nem ontológico - é apenas o instrumento que faz desabrochar o jus.

Natural que a descoberta das normas jurídicas se realizasse primeiro nos domínios da justiça comutativa, nos horizontes do direito privado.

Informes ainda os lineamentos do Estado, o encontro da razão humana com o direito haveria de brotar dos conflitos individuais de interêsses. $\mathrm{E}$, nisto, os romanos não se fizeram de rogados. Legaram-nos uma construção milenar quase perfeita do direito privado.

A justiça, porém, não é só individual, igualitária ou comutativa.

Ela só se integra, na verdade, se os aspectos sociais e públicos da justiça legal e da distributiva se fizerem presentes.

Ora, o direito público só poderia afirmar-se a partir da análise e conhecimento de um dos têrmos da relação - a sociedade organizada, ou o Estado.

E essa racionalização do Estado, como sujeito ativo e passivo de direitos, em face do indivíduo, só haveria de realizarse à medida em que as necessidades sociais fôssem impondo à inteligência humana, por bem ou por mal, por meios pacíficos ou pela revolução, a consideração daqueles valores indis- 
pensáveis à configuração das normas de direito público correspondentes.

O lento processo histórico de sujeição do Estado ao direito resulta, portanto, da laboriosa descoberta, pela razão, das normas jurídicas, materiais e instrumentais, que convêm ao direito público, isto é, àqueles setores pertinentes à justiça legal e à justiça distributiva.

Nesta tarefa estupenda de conquista da justiça, em cujo limiar sempre nos encontraremos, continua a caber ao processo, mesmo em tais domínios do direito público material, um papel de extrema relevância.

$\mathrm{O}$ Estado de direito nasce à medida em que a administração, nas suas relações com os administrados, começa a sujeitar-se ao processo jurisdicional.

Aqui também a actio é um elemento preponderante para a descoberta do jus, não mais privatum, senão publicum.

As primeiras manifestações de sujeição jurisdicional, vamos encontrá-las "naquelas relações entre Estado e cidadão que, pela forma e pelo conteúdo patrimonial, mais de perto se assemelham às relações dos particulares entre si" (3).

Defrontamo-nos, assim, no direito romano republicano com a ficção de substituir-se o Estado devedor por um cidadão qualquer, para os fins de sujeitá-lo como réu à jurisdição.

$\mathrm{E}$, de igual modo, surge a pessoa jurídica do Fisco, como sujeito ativo das causae fiscales. Interessante é, contudo, observar, com WINDSCHEID (4), que o direito romano, considerando embora o fisco como pessoa jurídica, não personificava, através dêle, o complexo dos indivíduos reunidos em Estado, mas simplesmente a caixa, ou o patrimônio do Estado, do mesmo modo como se atribui às fundações a personalidade jurídica. "Pois que por fundação se entende só o patrimônio destinado a um determinado fim. Se êste se encarna num instituto - coisa que não é necessária - com a personificação do patrimônio concorre a personificação do instituto".

(3) - CAMMEO, "Comentario delle leggi sulla giustizia amministrativa", I, pág. 31.

(4) - "Diritto delle Pandette", trad. FADDA e BENSA, I, 1925, pág. 173. 
Isto explica a afirmação de SAVIGNY de que o fisco era "o próprio Estado, considerado como sujeito de relações de direito privado" (5).

Se, entretanto, permaneciam confusas e indistintas as relações de direito público e a afirmação dos direitos subjetivos públicos do indivíduo, conheceu, em compensação, o direito romano uma forma altamente evoluída de direito político-processual. Referimo-nos às ações populares, concedidas cuivis de populo, como proteção não do interêsse particular, mas do próprio interêsse da comunidade, em variadíssimos casos. "Algumas visavam a conservar a integridade ou 0 livre uso de coisas públicas, ou de coisas ao abrigo da proteção dos interditos (actio de albo corrupto, actio de sepulchro violatio, etc.); outras, a afastar perigos à integridade comum (actio de positis et suspensis, actio de bestiis); outras, ainda, a conservar a integridade das classes de homens livres e de escravos (assertio in libertatem, interdito de homine libero exhibendo, actio de collusione detegenda); outras mais a tutelar princípios fundamentais de ordem privada e familiar (actio de tabulis apertis, actio suspecti tutoris), ou a garantir a observância de preceitos acêrca do ordenamento dos encargos públicos e da assistência pública (ações concedidas pelas leis coloniais e municipais); outras, por fim, a suprir a inércia dos funcionários públicos em reivindicar um direito privado da comunidade (ação para o legado ad pias causas)"(6).

Mas, o direito público subjetivo do particular, o direito do administrado contra a administração, uti singulis e não uti civis, permaneceu confuso e indeterminado no direito romano.

Devemos, sem dúvida, aos povos germânicos "o reconhecimento mais consciente do direito público subjetivo e de sua garantia jurisdicional". Ao contrário da irresponsabilidade funcional dos agentes públicos, que o direito romano admitia como regra, o conceito germânico submetia os órgãos do Estado, mesmo o mais elevado, o rei, ao direito nacional, à lex terrae. O indivíduo lesado, pelo rei ou por outro órgão, em pretensão subjetiva tutelada pela lex terrae, podia postular os seus direitos, primeiro perante a assembléia do povo, depois 
perante o colégio dos homens-bons ou dos jurados, único tribunal capaz de definir a lei nacional e sancioná-la (7).

Eis porque o primitivo Estado germânico é um Justizestaat, Estado de justiça, anterior ao Polizestaat, Estado-polícia, gerado depois pelo absolutismo real.

Compreende-se e justifica-se, diante disto, a ufania de HABERLIN ao exclamar, em 1797, referindo-se ao Tribunal Cameral do Império (Reichskammergericht), fundado em 1495: " $\mathrm{E}$ uma felicidade que nós, alemães, possamos mover processos que são revoluções! Enquanto isto nos for lícito, e em conseqüência da reparação que nossas demandas podem assegurar-nos, estaremos garantidos contra as verdadeiras revoluções violentas" (8).

O maravilhoso paradoxo da revolução pacífica através do judiciário nada mais era, na verdade, que a afirmação no direito público, realizada com singular eficiência pelo Tribunal Cameral do Reich, da vocação pioneira e permanente do processo de desbravador do direito, agora nos domínios até então quase inviolados do jus publicum.

A tal ponto chegou a afinação do instrumento processual, no antigo Justizestaat do Reich imperial, no sentido da proteção dos direitos subjetivos públicos do indivíduo, que vamos encontrar, aí, nessa época recuada, o antecedente claro e manifesto de nosso tão justamente exaltado mandado de segurança. "Nos casos em que se tratasse de atos de govêrno nullo modo justificabilia ou se ameaçasse um damnum irreparabile, os súditos tinham ação para reclamar dos tribunais imperiais um mandatum sine clausola. O pressuposto dêste processo era a lesão de um direito subjetivo, e a teoria e a prática excluiam a distinção entre direito público e direito privado. E por longo tempo a competência, a propósito, do império, foi inconteste, pois que a discussão versava sôbre a extensão dos poderes de polícia dos senhores territoriais, no limitar os direitos dos súditos" (9).

(7) - CAMMEO, op. cit., pág. 33.

(8) - "Handbuch des Teutschen Staatsrecht", II, 1797, pág. 467, apud WALTER JELLINEK, "Verwaltungsrecht", 3 Aufl., Berlim, 1931.

(9) - CAMMEO, op. cit., pág. 34, citando LONING, GNEIST, EAHR e SARWEY. 
O Estado-polícia posterior eliminou o salutar poder revolucionário dos tribunais em matéria de direito público - e disto um dos exemplos mais frisantes é o célebre edito de Saint Germain, de fevereiro de 1641, ao que parece do próprio punho de RICHELIEU, no qual se repele a pretensão do Parlamento de Paris de censurar a administração e pedir contas do manejo dos negócios públicos, e se convida os magistrados a se contentarem com o poder que os torna juízes da vida do homem e dos bens dos súditos, e se os proibe de ocuparem-se das coisas do govêrno, que não pertence senão ao príncipe ${ }^{(10)}$.

A revolução francesa, com o dogma absoluto da independência dos poderes, como defesa contra os abusos dos Parlamentos, manteve o absolutismo da administração, e reduziu o juiz a um oráculo inerte da vontade do legislador.

O moderno Estado de direito, contudo, se, de um lado, veio submeter a administração à legalidade e, portanto, à jurisdição - de outro, procurou resguardar em favor da administração a esfera de liberdade indispensável à consecução de seus fins, radicados no interêsse público, e impor também formas processuais definidas e específicas para a composição dos conflitos entre ela e o particular.

A disciplina a que o princípio de legalidade sujeitou a relação jurídica Estado-indivíduo, constitui, essencialmente, no reconhecimento de uma ação discricionária administrativa imune à jurisdição, e na imposição do due process of law, concebido como garantia de defesa e como limite, também, ao arbítrio do judiciário.

Tem-se acentuado, na doutrina, uma tendência moderna a limitar, pelas vias de contrôle, a ação administrativa, mesmo quando discricionária (11).

Essa orientação não nos parece defensável. Sem grave ofensa à justiça legal, não pode o legislador recusar à administração o poder de guiar-se segundo critérios não-jurídicos, de conveniência e oportunidade, para a satisfação dos fins que

(10) - LENTiNI, "La giustizia amministrativa", pág. 9, citando LAFERRI亡̀RE, "De la juridiction administrative", pág. 157.

(11) - SEABRA FAGUNDES, "O contrôle dos atos administrativos pelo poder Judictário", 3.a ed., pág. 119. 
lhe são próprios, isto é, para a satisfação das necessidades coletivas, em constante "devir", que lhe cumpre ocorrer.

Daí QUEIRó definir a discricionaridade como "a faculdade de escolha, concedida pelo legislador à administração, dentre uma série limitada de bens jurídicos adequados à satisfação de uma certa necessidade pública" (12). Isto não significa que os agentes públicos não sejam "obrigados a proceder a uma ponderação honesta do interêsse ou do valor de cada medida". Mas, "a obrigação legislativa é só a de procederem os agentes à melhor apreciação; qual seja, contudo, a melhor apreciação, é coisa que já não depende do legislador, é do livre juízo da Administração" (13).

Ou, no dizer de QUEIRÓ, "o agente tem, subjetivamente, de determinar-se pelo fim da satisfação ótima da necessidade tutelada" (14).

A consecução de tal fim é e deverá ser, contudo, insuscetível de jurisdição, se o agente se manteve no reto exercício do poder - dever que lhe incumbe. Êsse limite à jurisdição é, a nosso ver, indispensável para assegurar-se o devido respeito à justiça legal, no que concerne à posição instrumental do Estado, aos direitos - deveres inerentes à sua função administrativa.

Os vícios do ato administrativo podem concernir à manifestação da vontade, ao motivo, ao objeto, à finalidade e à forma (15).

$\mathrm{O}$ ato administrativo vinculado está, evidentemente, sob todos os aspectos, sujeito à jurisdição.

$\mathrm{O}$ ato discricionário a ela, contudo, também se subordina naqueles de seus aspectos regulados taxativamente pelo legislador, isto é, quanto à manifestação de vontade do agente (vícios de incompetência e de excesso de poder) e quanto à forma (vício de nulidade).

(12) - "O poder discricionário da administração", Coimbra, 1948, pág. 245.

(13) - QUEIRO, op. cit., pág. 268.

(14) - Op. cit., pág. 277.

(15) - SEABRA FAGUNDES, op. cit., pág. 76. 
Sendo, em regra, através da função administrativa que o Estado se põe em contacto com o indivíduo, é a propósito de seu exercício que poderão surgir conflitos de interêsses nas relações entre Estado e particular (16).

A lide será o choque de pretensões antagônicas do administrado e da administração, cuja composição mediante a descoberta e declaração da norma jurídica concreta, conveniente aos interêsses desavindos, constituirá o escopo da função jurisdicional, a ser solicitada através do remédio processual adequado.

Em regra, os remédios processuais comuns são de livre utilização por qualquer das partes.

Na prática, contudo, a administração raras vêzes assume a iniciativa de propor a demanda.

A razão consiste em que, embora o ato administrativo não seja em si mesmo e por natureza executório, costuma êle, entretanto, muitas vêzes, receber da lei a outorga de executoriedade direta. E considerando-se que cabe à administração promover o bem comum e, portanto, agir no conflito com os particulares, como diria CARNELUTTI, curial é que a reação a êstes caiba, quando entenderem que a ação administrativa se ressente de quaisquer dos vícios acima apontados.

O princípio, entretanto, é êste: quando a lei não conferir executoriedade própria ao ato administrativo, na hipótese de resistência do particular, o fim visado pelo Poder Público e a sua execução só poderão lograr-se mediante ação judicial, em que a administração surja como autora.

Daí o afirmar-se que quaisquer remédios processuais poderão ser utilizados pelas partes em conflito, podendo a ação respectiva assumir, indiferentemente, a natureza declaratória, constitutiva ou condenatória, conforme o tipo de pretensão manifestado.

Esta regra geral, entretanto, não esgota o problema da forma processual para êste tipo de litígio. É que a relação jurídica de direito público, pela complexidade dos valores em 
conflito e pelos fins diversos e antinômicos — individuais e sociais - a que tendem os sujeitos em lide, deve postular necessàriamente remédio processuais específicos para a pronta solução da controvérsia, estranhos àqueles em que comumente se resolvem as lides privadas.

A hierarquia maior dos valores de direito público a serem tutelados, pertinentes à administração ou ao administrado, exige formas processuais mais expeditas, impondo-se aqui, mais do que nunca, o respeito ao princípio de economia, pela necessidade pública fundamental, de um lado, de obter-se a certeza da legalidade da ação administrativa; de outro, de permitir-se que esta logre alcançar os fins legítimos, acaso embaraçados pelo indivíduo, no mais breve tempo possível.

Sem prejuízo, portanto, dos remédios processuais comuns, deve a ordem jurídica proporcionar remédios específicos para a solução de tais contendas.

No direito brasileiro, podemos apontar como remédios processuais específicos da administração o processo judicial de desapropriação e o executivo fiscal.

São, por sua vez, específicos contra a administração o habeas-corpus, o mandado de segurança e a ação popular.

A desapropriação de bens de particulares é lograda, em regra, mediante simples ato administrativo, vedado ao Poder Judiciário o exame do mérito da declaração de utilidade pública (art. 11 do decreto-lei 3.365, de 21/6/41).

Nestas condições, na ação de desapropriação, a solução do litígio entre administração e administrado se limita ao ar-bitramento judicial do valor da coisa expropriada.

Apesar disto, a ação é de natureza constitutiva, porque a sentença que fixar o preço da indenização possui um duplo efeito: substitui a propriedade do particular pelo sucedâneo do valor arbitrado, e subroga no preço os eventuais ônus ou direitos que recaíam sôbre o bem expropriado (art. 31 do decreto-lei 3.365). 
A ação executiva fiscal representa o reflexo processual da presunção de legalidade dos assentamentos do erário. Essa presunção inverte o ônus da prova. Ao invés de o credor - no caso, o fisco - provar a legitimidade do crédito, cabe ao réu, executado, a prova da ilegalidade da pretensão de cobrança.

A inscrição da dívida na repartição fiscal opera como título executório líquido e certo, equivalente à sentença, para os fins do procedimento executivo de coerção sôbre o patrimônio do devedor (arts. $2^{\circ}$ e $6 .^{\circ}$ do decreto-lei 960 , de ... $17 / 11 / 38)$.

Considerando que a lei, ùltimamente, tem facultado à administração meios de coerção indiretos sôbre o patrimônio do devedor, mais eficazes que a ação executiva (proibição de venda de estampilhas, de viagem ao exterior, etc.), do mesmo modo que permite a execução forçada do contribuinte quando funcionário, por via administrativa, mediante desconto em folha de pagamento - SEABRA FAGUNDES registra, com acêrto, a modificação operada no sentido da ação executiva fiscal, que, de privilégio do erário, passa a constituir-se em legítima tutela dos interêsses do executado, pela ampla defesa de mérito que lhe permite produzir no processo (17).

Embora não se trate de remédios processuais específicos da administração, cumpre mencionar, pelo destaque que lhes empresta o Código de Processo Civil, a ação cominatória e as ações de nulidade de patente de invenção e de marca de indústria e de comércio.

A primeira cabe à administração "para coibir o indivíduo ao cumprimento das diversas obrigações públicas, que consistam em prestações de suportar, fazer e não fazer" (18). Claro está que a discriminação de ações cominatórias próprias da União, Estados e Municípios, constante dos incisos X e XI, do art. 302 do C.P.C., é meramente exemplificativa. Sempre que o Poder Público quiser executar tais tipos de obrigação, sem para tanto possuir o necessário poder legal, deverá recorrer à ação cominatória, como remédio comum de proteção.

Quanto às ações de nulidade de patente e marca de in-

(17) - Op. cit., pág. 354.

(18) - SEABRA FAGUNDES, op. cit., pág. 433. 
dústria, os dispositivos do C.P.C., repetidos pelo Código de Propriedade Industrial, não impõem nenhum procedimento específico, limitando-se a consagrar-lhes o rito ordinário. Podem ser elas propostas tanto pela administração, quanto pelo particular.

No primeiro caso, justifica-se a ação judicial ao invés da simples cassação administrativa do privilégio, tendo-se em vista o efeito erga omnes do registro anterior, e o conseqüente interêsse moral da administração de ver declarada a ilegalidade de seu próprio ato pelo poder jurisdicional.

O direito brasileiro seguiu com não menor brilho a luminosa trajetória do direito anglo-americano, no que concerne à proteção pronta e eficaz dos direitos subjetivos públicos do particular.

Esta proteção haveria de lograr-se: primeiro, mediante a descoberta de normas instrumentais, de construção jurídico-processual expedita; segundo, mediante a elevação de tais formas e remédios processuais "à natureza de garantia exigível per se ipsa como direito constitucional" (19).

Para atingir tal objetivo, notável tem sido no direito brasileiro o trabalho integrador da doutrina e da jurisprudência.

Do habeas-corpus, nascido no Império, sob inspiração do direito inglês, no art. 340 do Código de Processo Criminal, e erigido em garantia constitucional pelo art. $72, \S 22$, da Constituição de 91 , haveria de nascer, graças à genial pregação de RUY, acolhida em "memorabilíssimo trabalho construtivo pela jurisprudência" (20), a notável extensão do instituto à proteção ampla dos direitos subjetivos públicos, à semelhança dos writs norte-americanos - "latitude esta que, em país algum, jamais se lhe reconhecera" (21).

Falha, na prática, a ação especial para a invalidação dos atos da administração lesivos de direitos individuais, criada pela lei n. ${ }^{\circ} 221$, de 1894, o mesmo gênio de RUY BARBOSA

(19) - PONTES DE MIRANDA, "História e Prática do Habeas-Corpus", § 52, pág. 173.

(20) - SEABRA FAGUNDES, op. cit., pág. 286.

(21) - SEABRA FAGUNDES, op. cit., pág. 286. 
lançou mão, para tal fim, dos interditos possessórios, em parte acolhidos, neste sentido, pelo Supremo Tribunal e pelo Poder Legislativo, "êste, decidindo-se a ampliar o interdito proibitório e a manutenção de posse à defesa dos contribuintes contra a cobrança de alguns impostos ilegais (lei n. $0^{0} 3.185$, de 1904)" (22).

Segundo a pregação de RUY, o habeas-corpus se destinaria à proteção das pessoas, os interditos à proteção dos bens.

Confinada a extensão do habeas-corpus, pela reforma constitucional de 26, às suas linhas tradicionais de remécio de proteção ao direito de locomoção e à liberdade física do indivíduo - sazonada se encontrava a seara para o nascimento de nosso mandado de segurança, cuja origem e finalidade são de todos conhecidas.

O que cumpre, contudo, assinalar nesta notabilíssima evolução, é o anseio pela busca da forma processual adequada, anseio a cujo clamor não se fizeram surdos os tribunais brasileiros. Ao contrário, pela conivência manifesta em desviar de seus fins remédios processuais apenas em parte adequados às novas exigências, forçaram o legislador à pesquisa da forma processual pertinente à eficaz proteção do direito subjetivo público do indivíduo.

$\mathrm{E}$, dêste modo, a tarefa de descoberta do direito que, no início dêste trabalho, indicáramos como própria da atividade do juiz, não se circunscreveu, entre nós, ao direito material - antes, pelo contrário, chegou ao ponto de influir decisivamente para a racionalização da norma instrumental, no sentido da descoberta de uma forma processual ótima, para ocorrer às necessidades processuais de proteção dos direitos do indivíduo, em face do Estado.

Esta notável afinação do instrumento, realizada pela jurisprudência brasileira, em matéria de direito público, como missão pré-legislativa e desbravadora de formas processuais ideais, está longe de dar-se por encerrada.

Muito pelo contrário, em tema de mandado de seguran-

(22) - ALCANTARA MACHADO, apud CASTRO NUNES, "Do mandado de segurança", 2.a ed., pág. 17. 
ça, aí está a construção normativo-jurisprudencial do recurso ordinário, até hoje não regulado pelo legislador; a atribuição de eficácia suspensiva ao agravo contra decisão denegatória, para o fim de manter-se a liminar, jurisprudência revolucionária dos cânones processuais mais acatados, pois que importa em quebra do princípio da igualdade processual das partes, em favor do particular, já que o agravo da administração contra a decisão concessiva do mandado não possui efeito suspensivo. E esta desigualdade processual de eficácia para o mesmo recurso, conforme utilizado pelo administrado ous pela administração, é consagrada como compensação da desigualdade que se presume existir fora do processo, entre o indivíduo e o poder do Estado.

Notável, ainda, a construção jurisprudencial no que concerne às conseqüências da sujeição do ato judicial ao mandado de segurança, especialmente no que respeita à posição processual, no mandado, da parte adversária no processo em que se manifesta o ato impugnado. Os novos rumos desta extensão do remédio estão a abalar, certa ou erradamente limitamo-nos a registrar o fato - tôda a teoria dos recursos no processo civil, e a estabelecer maior confusão nas idéias já de si confusas que circulam na doutrina a respeito de litisconsórcio e da intervenção de terceiros no processo.

Mas, onde a criação-descoberta da normatividade processual maior esfôrço está demandando da inteligência de nossos juízes, é no que se refere à ação popular, último e mais recente dos meios processuais específicos contra a administração, acolhidos pelo direito constitucional brasileiro. Ainda aqui, a jurisprudência se tem mostrado bandeirante da legislação ordinária, até agora ausente na regulamentação do novo instituto processual.

Não cabe nos limites destas linhas qualquer informação sôbre o histórico e natureza da ação popular, de resto, assaz conhecidos. Importa apenas lembrar que, através dela, o de que se cuida proteger é não um direito público do indivíduo, senão que um direito da própria coletividade, de que o autor se faz substituto processual. O direito de exercício da ação popular enquadra-se, assim, entre os direitos cívicos fundamentais, e esta característica cívico-política é que faz com que o instituto se estenda também ao próprio direito eleitoral. 
Pois bem, esplêndida, sob todos os aspectos, como prova de aguda sensibilidade à necessidade política de um remédio processual eficaz aos fins da ação popular, é a forte corrente que pulsa em nossos tribunais no sentido de adaptar-se tal ação ao rito sumaríssimo do mandado de segurança, quando presentes também os pressupostos constitucionais dêste, relativos à certeza e liquidez do direito controvertido; no caso, o direito do ente público, lesado pelo ato da autoridade.

Êstes simples traços evidenciam como o direito processual constitucional, para usarmos a expressão de JOSE FREDERICO MARQUES, se elabora no Brasil - e se trata, neste domínio, para honra nossa, de elaboração de vanguarda no direito universal - se elabora sob o impulso decisivo do Poder Judiciário, o qual não mais se compraz em descobrir o ótimo jurídico adequado à conduta material das partes, mas se afana em encontrar também o ótimo processual indispensável à proteção dos interêsses públicos e politicos do indivíduo e do cidadão.

Até onde iremos nesta ânsia pioneira e pré-legislativa, de busca da norma instrumental ideal às necessidades da lide entre o Príncipe e o súdito, na ponderação exata dos valores em conflito?

Sem dúvida, marchamos em demanda de novos horizontes de maior glória para o direito público brasileiro. 